\title{
The Moderating Role of Familiarity in Fairness Perceptions of Revenue
}

\author{
Management Pricing \\ Jochen Wirtz \\ National University of Singapore \\ and \\ Sheryl E. Kimes \\ Cornell University School of Hotel Administration
}

Perceived fairness of revenue management (RM) pricing is a serious concern, as RM uses different prices for fundamentally the same service. The authors examine the effects of familiarity with an RM pricing practice, framing of prices, and fencing condition (i.e., whether a respondent was advantaged or disadvantaged by an RM price) on fairness perceptions. The authors conduct two experiments and find that familiarity moderated the effects of framing and fencing condition on consumers 'fairness perceptions. Specifically, framing and fencing condition had strong effects on perceived fairness when respondents were less familiar with a pricing practice. However, when familiarity was high, neither the framing nor fencing condition effect was significant. Our findings suggest that familiarity may be a boundary condition for prospect theory.

KEYWORDS: revenue management; perceived fairness; rate fence; framing; familiarity 
Revenue management (RM) has been practiced in the airline (Smith, Leimkuhler, and Darrow 1992), hotel (Hanks, Noland, and Cross 1992) and car rental industries (Carroll and Grimes 1995; Geraghty and Johnson 1997) for more than 15 years and has more recently attracted attention in other industries, including broadcasting, golf, health care, and restaurants (e.g., Born et al. 2004; Kimes and Wirtz 2003a, 2003b; Ng, Wirtz, and Lee 1999). RM is applicable to any business that has a relatively fixed capacity of perishable inventory (i.e., seats, rooms, tee times), that manages demand (either through reservations or wait lists), that has high fixed and low variable costs, and that has varying customer price sensitivity.

Pricing is a key strategic lever RM deploys (Kimes and Chase 1998). For RM pricing to be effective, customers who are willing to pay more must be prevented from taking advantage of a lower price targeted at a more price-sensitive segment. Because services are often place, time, and customer specific and capacity constrained, substantial opportunities exist for service providers to use price discrimination and to build effective rate fences between the segments. For example, a sports stadium can offer different prices based on seat location (a physical rate fence), customer age (a nonphysical rate fence), or perceived quality of the opponent (a nonphysical rate fence). Well-designed rate fences allow customers to self-segment on the basis of their willingness to pay and on service, transaction, and consumption characteristics. Table 1 provides an overview of common rate fences used in service pricing.

RM pricing and related rate fences can be perceived as unfair or even as price gouging, and fairness perceptions have been shown to be related to firm profitability (Kahneman, Knetsch, and Thaler 1986a, 1986b; Thaler 1985). If customers view a firm's practices as unfair, negative consumer responses are likely. Immediate attitudinal and affective responses include dissatisfaction (Oliver and Swan 1989a, 1989b), lower purchase intentions (Campbell 1999; 
Huppoertz, Arenson, and Evans 1978), heightened price consciousness and focus on the monetary sacrifices of a purchase (Xia, Monroe, and Cox 2004), and negative emotions such as disappointment, anger, and outrage (Austin, McGinn, and Susmilch 1980). Behavioral responses to perceived price unfairness range from complaining, asking for a refund, spreading negative word of mouth, to switching the provider (Huppoertz, Arenson, and Evans 1978; Xia, Monroe, and Cox 2004). Therefore, unless customers' fairness perceptions of RM and related rate fences can be well managed, short-term gains through RM may be offset by a negative impact on longer term profitability (Wirtz et al. 2003).

The focus of this study is on perceived fairness of RM pricing as the key dependent variable. Perceived fairness has been shown to be affected by the framing of an RM practice, whereby customers perceive economically equivalent pricing schedules as fairer when expressed as discounts rather than surcharges (Kahneman and Tversky 1979; Kimes and Wirtz 2003a). In addition to framing, we propose that perceived fairness is also affected by the fencing condition a customer is in. For example, customers who receive a lower price as the result of an RM practice (e.g., customers who benefit from off-peak pricing) are proposed to view the practice as fairer than those who pay a higher price (e.g., those who have to pay peak prices). Furthermore, and most important, we propose that such framing and fencing condition effects are moderated by customer familiarity with an RM pricing practice.

\section{CONCEPTUAL BACKGROUND}

After reviewing the relevant literature on perceived fairness, framing, and fencing condition, we will discuss how familiarity moderates the effects of framing and fencing condition on fairness perceptions. 


\section{Perceived Fairness and Rate Fences}

Perceived fairness is defined as whether an outcome and/or a transaction process are seen by consumers as reasonable, acceptable, and just (Bolton, Warlop, and Alba 2003). All fairness perceptions are comparative in nature (Xia, Monroe, and Cox 2004). Two conceptual comparative frameworks widely used to explain fairness perceptions are the principle of dual entitlement and the concepts of reference price and reference transaction.

The principle of dual entitlement states that most customers believe they are entitled to a reasonable price and the firm is entitled to a reasonable profit (Kahneman, Knetsch, and Tversky 1986a, 1986b). Dual entitlement further states that an increase in price is considered to be fair if it is due to a cost increase (e.g., an increase in procurement cost) but considered unfair if it is increased without any increase in cost (i.e., to increase profits). As such, if customers in a highrate fence scenario believe that increased prices are not due to cost increases, their beliefs about dual entitlement may be violated, and thus, they may view many RM pricing practices as unfair.

In addition to dual entitlement comparisons, consumers' perceived fairness of prices is often also based on comparative or highly similar transactions (cf. Xia, Monroe, and Cox 2004) or reference transactions (cf. Kimes and Wirtz 2003a). A reference price is defined as how much a customer thinks a service (or good) should cost. To assess the fairness of a price, customers often rely on the last price paid, the price most frequently paid, and market prices and posted prices (Kahneman et al. 1986a, 1986b). For example, customers may view the higher price charged during high-demand times as above their reference price, or their reference price may have already been shifted downward because of lower prices during low-demand periods. In either event, the "new" high-demand price may be perceived as less fair than before (Kimes and Wirtz 2003a). 


\section{Framing and Perceived Fairness}

All rate fences can be framed either as a discount or a surcharge to a regular price. Prospect theory suggests that consumers perceive prices framed as gains (i.e., discounts in a pricing context) as fairer than those framed as losses (i.e., surcharges or premiums), even if the situations are economically equivalent (Chen, Monroe, and Lou 1998; Kahneman and Tversky 1979; Thaler 1985). For example, a hair salon may decide to charge a higher price on Fridays and Saturdays. It can either present the higher price as a premium over its regular price (i.e., regular $\$ 45$, plus $\$ 10$ for Friday/Saturday service), or it can position its weekday service as a discount from higher weekend prices (i.e., regular \$55, discount \$10 for Mondays to Thursdays). It has been shown that the framing of price differences as gains is perceived as fairer than when framed as losses (Kimes and Wirtz 2003a). Rather than focus on the framing main effect, we will later argue that framing effects are moderated by customer familiarity with a rate fence.

\section{Fencing Condition and Perceived Fairness}

Xia, Monroe, and Cox (2004) suggest that perceived price differences can lead to perceptions of advantaged inequality (i.e., the consumer pays less than the reference price or another consumer) or disadvantaged inequality (i.e., the consumer pays more). Therefore, we expect that for an equivalent magnitude of price inequality, there will be a smaller degree of perceived unfairness (if any at all) when the inequality is to the buyer's advantage than when it is to his or her disadvantage (Martins 1995; Ordofiez, Connolly, and Coughlan 2000; Xia, Monroe, and Cox 2004). However, the current RM literature largely ignores the fact that every RM pricing practice can be seen from two perspectives-one from the person paying the higher price who is prevented by an effective rate fence from taking advantage of the lower price (e.g., a nonstudent who pays a full price and cannot take advantage of a special student rate) and the 
other from the person who is able to take advantage of a lower price through the same fencing mechanism (e.g., a student who benefits from the discounted student rate). In our studies, we address this issue for the first time by explicitly examining fairness perceptions of both the fence-advantaged and the fencedisadvantaged customer.

In sum, this discussion indicates that customers who receive an advantage from an RM pricing practice (i.e., are fence advantaged) consider the price they pay as fairer than customers who are fence disadvantaged. As with framing, we propose that this relationship is moderated by familiarity.

\section{Familiarity as Moderator of Framing and Fencing Condition Effects}

Customers are affected by community norms of reference prices, and customers' perceptions of fairness are judged relative to these community norms (Kahneman, Knetsch, andTversky 1986a, 1986b). In an RM context, there is also evidence that customers are shifting their fairness perceptions to community norms (Kimes 1994; Kimes and Noone 2002). This suggests that as a market becomes more familiar with RM practices, the unfairness perceptions of those practices decline over time. In addition, we propose that familiarity with an RM practice moderates framing and fencing condition effects on perceived fairness. Specifically, we suggest that framing and fencing condition effects become weaker as customers become more familiar with RM pricing practice. We use two related theoretical explanations for this prediction.

First, Xia, Monroe, and Cox (2004) extended social comparison theory to perceived fairness and suggest that consumers compare transactions (including prices paid). When the degree of perceived similarity between transactions is high, consumers have little differential information to explain price differences. As a result, they tend to believe that they are entitled to 
equal prices and are likely to perceive price differences as unfair. In contrast, when two transactions are seen as dissimilar, price discrepancies are seen as less unfair or even as fair.

Familiarity with RM and rate fences should lead customers to view transactions on each side of the rate fence as dissimilar (e.g., consumers understand that the same meal at lunch is a different transaction from that at dinner) and therefore compare the price they paid to consumers within the same fencing condition rather than across fencing conditions. If less familiar customers do not understand the difference between transactions across rate fences, these transactions are more likely to be viewed as unfair (cf. Major 1994; Xia, Monroe, and Cox 2004). This would then lead to upward comparisons if the consumer is looking "up" to others who paid a better price (i.e., to other customers in the fence-advantaged situation) or to downward comparisons to those who paid a higher price. That is, fencing condition will matter more for customers who are unfamiliar with a rate fence. Furthermore, for both upward and downward comparisons across rate fences, losses and gains will be experienced. This suggests that the framing of price differences is also likely to matter more to customers unfamiliar with a rate fence.

Second, justification or explanation of an act can influence fairness perceptions (Bies and Shapiro 1987; Greenburg 1988). Customers in unexpected negative situations (as would be the case for unfamiliar customers in a fence-disadvantaged condition) will be motivated to search for causal explanations (cf. Winer 1986), and the attributions tend to be negative for firms that tend to be suspected of price gouging (cf. Bolton, Warlop, and Alba 2003). As a result, consumer perceptions of fairness are likely to be affected. In positively framed and fence-advantaged situations, consumers are expected to exhibit a self-focused bias with little effect on perceived fairness. Conversely, customers who are familiar with an RM practice are likely to have already 
adjusted their reference transaction and reference price with less or even no impact on perceived price fairness.

In sum, we hypothesize the following familiarity-framing and familiarity-fencing condition interaction effects (see Figure 1):

Hypothesis 1: Framing has a stronger effect on the pricing fairness perception of customers who are less familiar with an RM pricing practice than on customers who are more familiar with that practice.

Hypothesis 2: Fencing condition has a stronger effect on the pricing fairness perception of customers who are less familiar with an RM pricing practice than on customers who are more familiar with that practice.

\section{METHOD OVERVIEW}

\section{Research Design}

We conducted two studies. Study 1 employed a $2 \times 2$ between-subjects full factorial design, with familiarity (familiar vs. unfamiliar RM practice) and framing (discount vs. surcharge) as the independent variable and perceived fairness as the dependent variable. Set in a restaurant context, familiarity was manipulated by using an RM practice that is widely understood (peak hour pricing) and one that is relatively rare (duration control pricing). A true experimental approach was used to maximize internal validity.

Study 2 built on the first study, to extend our understanding of the working of familiarity and test for interactions with our second variable, fencing condition. The study was set in a hotel context. It employed a $2 \times 2 \times 2$ (Familiarity $\times$ Framing $\times$ Fencing Condition) design. Here, familiarity was investigated by a quasi-experimental approach to test the robustness and enhance 
the external validity of the findings for our key variable. Framing (discount vs. surcharge) and fencing conditions (customer was in the low price situation vs. in the high price situation) were manipulated using a between-subjects full factorial design.

A scenario method with role-playing was used for both studies to reduce potential problems introduced by personal circumstances to the research context (Havlena and Holbrook 1986) and to reduce experimental noise by employing a standardized setting for all subjects (Cook and Campbell 1979). Although not without shortcomings, the role-playing scenario approach has been used frequently in consumer behavior research (e.g., Dabholkar 1996; Wirtz and Bateson 1999) for much the same reasons as in our studies.

Measures

Perceived fairness. In Study 1, perceived fairness was measured with a two-item, 7-point scale adopted from the Perceived Price Fairness scale used by Campbell (1999). The first item used the statement "The situation is" and was anchored by $1=$ very fair and $7=$ very unfair. The second item used the statement "This price is not fair" and was anchored by 1 = strongly agree and 7 = strongly disagree.

We modified the Perceived Fairness scale for Study 2 to also capture the ethical and acceptability aspects of perceived fairness (Kimes 1994), as these issues were mentioned in our follow-up discussions with participants in Study 1. Specifically, we used the statement "I consider the hotel's pricing policy as ..." and then presented three semantic differential scale items. The first was anchored by very fair and very unfair (Campbell 1999), the second by very ethical and very unethical, and the third by very acceptable and very unacceptable (Kimes 1994). Both measures displayed good internal consistency, the correlation coefficient was .82 in Study 1, and the Cronbach's alpha was .92 in Study 2. 
Perceived fairness, our dependent variable, was immediately measured after participants had been exposed to their respective experimental scenario. All other measures, including the familiarity manipulation checks, were placed after the Perceived Fairness scale. Placing the dependent variable scale first had the advantage of obtaining an immediate and direct response to the scenario and its manipulations and at the same time avoiding potential demand effects triggered by asking participants to respond to other scales first.

Familiarity. A familiarity scale was used as a manipulation check in Study 1 and as an independent variable in the quasi-experimental design in Study 2. The check consisted of two semantic differential scale items adopted from Oliver and Bearden (1985). The first statement asked about the respondent's familiarity with the buffet pricing scenario in Study 1 and about different hotel prices via a hotel's own Web sites and via third-party Web sites such as Expedia in Study 2. The item was anchored by very unfamiliar and very familiar. The second item asked how often they have seen, heard, or experienced such a way of pricing, anchored by never and very often. The correlation coefficients were high, with .82 in Study 1 and .89 in Study 2. Samples and Research Procedures

Self-administered intercept surveys were conducted. The surveys were kept short and generally did not take longer than $3 \mathrm{~min}$. For Study 1, data were collected in a city area with a high concentration of hotels and restaurants, and the data for Study 2 were collected in a parttime MBA class, the Central Business District, and the Changi International Airport in Singapore. The final samples used for analyses were 270 for Study 1 and 170 for Study 2.

For Studies 1 and 2, 55.2\% and 50.6\% were female, respectively. For Study 1, 26.3\% were 25 years and younger and 11.1\% were 40 years and older. For Study 2, 65.9\% were 25 years and younger and $8.8 \%$ were 40 years and older. 


\section{STUDY 1 (RESTAURANT)}

\section{Study Context and Manipulations}

We conducted a series of pretests to identify appropriate contexts for our two studies. For Study 1, we needed a service where we could use two rate fences: one fence with which respondents were highly familiar and another with which they were not very familiar. We selected a buffet in a five-star hotel restaurant, where there is only one price the customer pays (excluding drinks) and consumers can easily compare prices. Familiarity was manipulated at two levels. We used peak/off-peak (dinner/lunch) pricing as the familiar RM practice. The data were collected in Singapore, where buffet lunches and dinners are common and customers are quite familiar with the differential prices charged. For the unfamiliar RM practice, we used duration control pricing, a practice uncommon in Singapore. Our pretests confirmed that Singaporeans were generally unfamiliar with this RM practice.

For the high familiarity manipulation, participants were presented with a lunch/dinner pricing scenario. The buffet prices presented were Singapore Dollars S\$30 for lunch and S\$40 for dinner (US\$1 = S\$1.57). For the low familiarity manipulation, a duration control pricing scheme was presented. Participants were told that the price of a dinner buffet was S\$40 if the meal took more than $1 \mathrm{hr}$ and that it was $\mathrm{S} \$ 30$ if the meal took less than $\mathrm{l} \mathrm{hr}$.

Framing was manipulated at two levels (discount or surcharge). In the discount condition, the lunch price was presented as a S\$10 discount off the dinner price in the peak/off-peak pricing scenario or a S\$10 discount was given if the meal took less than $1 \mathrm{hr}$ in the duration control pricing scenario. In the surcharge condition, the price of the dinner was presented as a charge of 
S\$ 10 over the price of the lunch price or as a S\$ 10 higher price if the meal took more than $1 \mathrm{hr}$. The detailed scenarios are shown in the appendix.

A one-way ANOVA was run to check whether the two RM practices were perceived as intended. The RM practice main effect was significant on familiarity, $F(I, 268)=98.5, p<.001$, eta square $=.27$, and the means were in the anticipated direction with $\mathrm{X}^{\wedge}$ sub peak/off peak pricing $\wedge=4.47$ and $\mathrm{X}^{\wedge}$ sub duration pricing $\wedge=2.50$ ' suggesting a successful familiarity manipulation.

\section{Hypotheses Testing}

The hypotheses were tested using ANOVA (see Table 2 for the means across experimental conditions, Table 3 for the ANOVA results, and Figure 2 for a plot of the significant interaction effect). Hypothesis 1 predicted that framing would have a stronger effect for customers less familiar with an RM pricing practice than for customers who were more familiar with it. As shown in Table 3, the hypothesized familiarity and framing interaction effect was significant, $\mathrm{F}(\mathrm{I}, 269)=8.6, \mathrm{p}<.01$. Contrast effects showed that framing had a significant effect on perceived fairness when participants were less laminar $\left(\mathrm{X}^{\wedge}\right.$ sub discount/low familiarity^ $=4.18$ vs. $\mathrm{X}^{\wedge}$ sub surcharge/low familiarity^ $\left.=3.08\right), \mathrm{F}(1,269)=19.3, \mathrm{p}<.001$. When participants were highly familiar, framing effects were no longer significant $\left(\mathrm{X}^{\wedge} \mathrm{sub}\right.$ discount/low familiarity^ $=4.40$ vs. $\mathrm{X}^{\wedge}$ sub surcharge/high familiarity $\left.{ }^{\wedge}=4.34\right), \mathrm{F}(1,269)=0.07$, $\mathrm{p}=.80$, supporting Hypothesis 1 .

\section{STUDY 2 (HOTEL)}

\section{Study Context and Manipulations}


For Study 2, we needed an RM context where respondents would show a high variance in familiarity, as we intended to use a quasi-experimental design where we would measure rather than manipulate familiarity. We found that differential pricing of hotel rooms via different electronic channels showed the highest variance in familiarity in our pretest sample and was therefore selected. Specifically, we used hotel Web site pricing versus the pricing on third-party Web sites such as Expedia, Priceline, and Travelocity, which are sometimes used to clear excess inventory at low prices.

Framing was manipulated at two levels (discount or surcharge). For the discount condition, the room rate on a third-party Web site was presented as US\$25 less than the room rate shown on the hotel's main Web site. For the surcharge condition, the room rate on the hotel's Web site was presented as US\$25 higher than the room rate shown on a third-party Web site.

The fencing condition was manipulated at two levels (fence advantaged or fence disadvantaged). For the fence-advantaged condition, the customer had paid a lower room rate (i.e., he or she made the reservation through a third-party Web site), whereas for the fencedisadvantaged condition, the customer had paid a higher room rate (i.e., made the reservation through the hotel main Web site) before finding out about the differential pricing of the two electronic channels. see the appendix for the scenarios employed.

We conducted a three-way split of the sample based on familiarity scores and used the high and low familiarity cells for hypothesis testing. This method resulted in respondents around the scale midpoint (i.e., "neutral" respondents) being taken out from the analysis and enabling us to contrast the low and high familiarity cells. The means were significantly different at $\mathrm{t}=33.7, \mathrm{p}$ $<.001$, with $\mathrm{X}^{\wedge}$ sub low familiarity^$=2.67$ and $\mathrm{X}^{\wedge}$ sub high familiarity^$=6.04$, allowing the data to be used for hypotheses testing. 


\section{Hypotheses Testing}

A three-way ANOVA including all independent variables (i.e., familiarity, framing, and fencing condition) was conducted. The two hypothesized two-way interactive effects reached significance, namely the interactive effects of familiarity and framing, $F(I, 162)=4.9, p<.05$, and familiarity and fencing condition, $\mathrm{F}(1,162)=5.0, \mathrm{p}<.05$, on perceived fairness (see Table 3 and Figure 3).

Familiarity $\times$ Framing Interaction (Hypothesis 1 ). As with Study 1 , the findings confirmed that framing had a stronger effect on perceived fairness when respondents were less familiar with an RM practice. Specifically, the results showed that framing had a significant effect on perceived fairness when_participants were less familiar $\left(\mathrm{X}^{\wedge}\right.$ sub discount/unfamiliar^${ }^{\wedge}=$ 3.91 vs. $\mathrm{X}^{\wedge}$ sub surcharge/unfamiliar^ $\left.{ }^{\wedge}=2.98\right), \mathrm{F}(1,169)=11.70, \mathrm{p}<.001$, and did not reach significance when respondents were familiar with the $\mathrm{RM}$ practice $\left(\mathrm{X}^{\wedge}\right.$ sub discounts/familiar $\wedge=$ 4-38 vs. $\mathrm{X}^{\wedge}$ sub surcharge/familiar^$\left.{ }^{\wedge}=4.31\right), \mathrm{F}(1,169)=.06, \mathrm{p}=.81$. The $\mathrm{F}$ values and means plotted in Figure 3 confirm that as hypothesized in Hypothesis 1, framing had a stronger impact on participants with low familiarity than on participants with high familiarity.

Familiarity $\times$ Fencing Condition (Hypothesis 2). The fencing condition only had a significant effect in the low familiarity condition $\left(\mathrm{X}^{\wedge}\right.$ sub fence.advantaged/unfamiliar $\wedge=3.87$ vs. $\mathrm{X}^{\wedge}$ sub fence-disadvantaged/unfamiliar^ $\left.{ }^{\wedge}=3-02\right), \mathrm{F}(1,169)=9.82, \mathrm{p}<.005$, and was insignificant in the high familiarity condition $\left(\mathrm{X}^{\wedge}\right.$ sub fence-advantaged $/$ familiar $\wedge=4.34$ vs. $\mathrm{X}^{\wedge}$ sub fence-disadvantaged/familiar $\left.\wedge=4.35\right), \mathrm{F}(1,169)=.003, \mathrm{p}=.96$. The $\mathrm{F}$ values and means plotted in Figure 3 confirm that as hypothesized in Hypothesis 2, fencing condition had a higher impact on participants with low familiarity than on participants with high familiarity. 


\section{CONCLUSION AND DISCUSSION}

We found that familiarity moderated the effects of framing and fencing condition on fairness perceptions. Framing prices as a discount or a surcharge or placing respondents into a fence-advantaged or -disadvantaged situation, had a significant impact on perceived fairness only for those unfamiliar with the respective RM practice. Respondents who were familiar with the practice were not significantly affected by the framing or fencing condition. The relationship is likely to be a continuum, whereby framing and fencing condition effects decline with increasing degrees of familiarity and, at high levels of familiarity, become insignificant.

These results expand our understanding of framing effects by including the concept of familiarity. Although our overall results support prospect theory (Kahneman and Tversky 1979) in that economically equivalent prices are perceived more favorably if framed as gains than losses, we also found that framing effects held true only when participants were less familiar with the pricing practice. It did not hold true when customers were familiar with the practice. High familiarity may be a boundary condition for framing effects in rate fences.

In addition to framing, we found that fencing condition, which has not yet been explored in the RM literature, is an additional variable that determines fairness perceptions and is moderated by familiarity. This finding also extends research in the pricing literature that has proposed that perceived price differences can lead to perceptions of advantaged inequality (i.e., the consumer pays less than the reference price or another consumer) or disadvantaged inequality (i.e., the consumer pays more), resulting in perceptions of unfairness (Xia, Monroe, and Cox 2004). Again, our findings suggest that familiarity is a boundary condition for this effect.

A possible explanation for the observed familiarity framing and familiarity-fencing condition interactions is the impact familiarity has on social comparison and consumer 
attribution processing. When consumers are familiar with a rate fence, they may see two ratefence conditions as different transactions (e.g., a dinner on a Tuesday night is a different transaction from the same dinner on a Friday night), which carry different reference prices, and consumers may therefore be less likely to make social comparisons with consumers in a different fencing condition. Attribution processes and subsequent unfairness perceptions may not be triggered as consumers do not need to search for causes or explanations for price differences. As a result, framing and fencing condition of price differences matter less for consumers familiar with a pricing practice.

In contrast, less familiar customers may be less able to see the dissimilarity between transactions related to different rate fences. As a result, these consumers are more likely to make social comparisons across fencing conditions (i.e., "I have to pay a surcharge," or "I don't get the discount") when evaluating the fairness of that pricing practice. As attributions are mostly triggered in negative situations (Winer 1986) and tend to be biased against firms (Bolton, Warlop, and Alba 2003), perceived price unfairness is a likely outcome of this process. In positive fencing conditions, attributions are less likely to be triggered, because buyers tend to be biased by their self-interest and be less motivated to seek attributions (cf. Weiner 1985; Xia, Monroe, and Cox 2004). Our findings imply that fairness researchers should not simply consider the perceived fairness of different practices but should also consider familiarity with those practices.

\section{Managerial Implications}

This study has a number of implications for management practice. First, given a choice, managers should always frame price differentials as discounts rather than surcharges. This will not have a significant impact on perceived fairness for those familiar with the RM pricing 
practice but will lead to improved fairness perceptions for those less familiar with it. For example, hotels and airlines have long used this practice and present most prices as discounts off of their high-rack rates and full fares.

Second, all effective rate fences will result in fence advantaged as well as fencedisadvantaged customers, and our results indicate that customers unfamiliar with a rate fence will respond negatively when put into a fence-disadvantaged pricing situation. Therefore, when embarking on any RM pricing practice, managers must ensure that customers are being educated about it. For example, if a golf course operator decides to charge different prices by time of day, day of week, and customer affiliation, the operator must ensure that customers are familiar with these practices. Familiarity can be enhanced in a number of ways, including brochures, signage, and employee explanations of price differentials.

It may also behoove managers to not be the first in their industry or geographic market to institute a particular RM practice, as customers may take a while to become familiar with it. For example, if a restaurant manager decides to levy a surcharge for reservations made for desirable tables (i.e., table location pricing), he or she may first want to check if other restaurants are using the same practice. The risk associated with being the first to introduce a RM pricing policy may outweigh the potential financial benefits associated with that policy. The policy may be successful, but it can take a while to achieve that success, and customer goodwill will suffer in the process.

On a more positive note, managers in industries not generally associated with RM may have an easier time introducing RM pricing practices today than traditional RM industries (e.g., airlines and hotels) had 10 to 15 years ago. Customers have become familiar with airline and hotel RM practices, and this familiarity may carry over to the pricing practices of other 
industries. A good example of this is movie theater pricing. Traditionally, movie theaters charged essentially the same price (except for age-based discounts) for all those viewing a movie at the same time. Recently, movie theaters have been emulating performing arts theaters and started pricing by not only day of week and time of day but also by seat location and have been met with little resistance.

\section{Directions for Future Research}

Understanding the impact of familiarity on perceived fairness is a relatively new area, and there are many potential avenues for extending the present study. We used social comparison and causal inferences to support our hypotheses. As our hypotheses were supported by our two data sets, a next step would be to untangle the underlying psychological processes that explain our observations and explore the relative importance of these processes and potential boundary conditions for them. For example, it would be important to confirm that surcharge and fencedisadvantaged price situations trigger attribution processes, whereas discount and advantaged situations do not (or do so to a less extent) and that those familiar with the practice do not (or do so to a less extent) engage in attribution processing.

In our two studies, we used scenarios with a fixed storyline and randomly assigned respondents to the experimental conditions. In many real-world settings, consumers can selfsegment and control on which side of a rate fence they consume. Perceived control has been shown to positively affect a wide range of feelings and evaluations, including pleasure and satisfaction (e.g., Bateson and Hui 1992). For example, in our duration control scenario, consumers in a real-life setting could control whether they spend less or more than 60 min at the buffet and therefore either pay the lower or higher price. Furthermore, the control customers have over rate fences can vary from no control (e.g., age-related fences) to complete control 
(e.g., the duration spent in an ice rink). Perceived control in a fencing situation could take the form of decisional control (e.g., "I can decide how long I will stay at the buffet") and cognitive control (e.g., "I understand why the firm uses this pricing fence," and "I understand that it benefits me by reserving capacity for me at peak times"). Understanding the role of perceived control in fairness judgments of service prices is an intriguing area for further investigation.

We focused on fairness perceptions, but other dependent variables, psychological as well as behavioral variables, should be included in the future research. For example, Xia, Monroe, and Cox (2004) suggested that fence-disadvantaged consumers may feel anger or outrage, whereas fence-advantaged consumers might feel unease or guilt. In an RM context, anecdotal evidence seems to suggest that in addition to unease, customers in fence-advantaged situations may feel happy or lucky that they managed to obtain low rates. Again, familiarity may interact with emotional responses. For example, in an airline context, customers may be used to a wide range of prices and therefore not experience guilt or unease but may feel less comfortable in other contexts where they are not used to wide price ranges (e.g., in professional services). We hypothesize that fairness perceptions are a mediator between rate fence condition, familiarity, and emotional responses and behaviors. Behavioral variables that could be included in future work are purchase decision making when faced with a particular rate fence and repeat purchase (intent) after having experienced a particular fence.

In our two studies, familiarity has been shown to be a boundary condition for framing effects as would be predicted by prospect theory. Our findings suggest that familiarity might be a soft boundary condition for framing effects in general, whereby more informed and familiar individuals respond less strongly to framing than their less familiar counterparts. Future work in other contexts would be an interesting extension. 
Finally, from a managerial perspective, it is important to understand when and how consumers should be educated about new RM pricing schemes. There might be differences in the ease of familiarizing and educating customers about different types offences. For example, it might be that physical fences (e.g., business vs. economy class) are more tangible and more easily understood and therefore could be communicated faster and at a lower cost than nonphysical fences (e.g., a requirement to stay over a weekend night in a hotel). Similarly, fences related to customer characteristics with a social dimension (e.g., lower prices for senior citizens, students, or low-income households) might be easier to communicate than fences related to "invisible" customer characteristics, such as account balance or annual transaction volume.

As with any research, this study is not without limitations. The studies were conducted in a single country (Singapore) using scenario-based experimental designs in two industry contexts (restaurants and hotels). In addition, the design of Study 1 could be improved by explicitly controlling for the perceived quality of the restaurant (e.g., a 60-min fence may signal a lower quality restaurant, similar to fast food) and for other potential reasons that may extend the stay to beyond 60 min (e.g., crowding or slow service). Future work should replicate and extend our study across other countries, methods, and contexts to enhance the external validity of our findings. 


\section{ACKNOWLEDGEMENT}

The authors gratefully acknowledge the research assistance of Hsiao Wei Chua and Denis Tan, and the financial support from the National University of Singapore. 


\section{APPENDIX}

\section{STUDY 1: MANIPULATIONS OF FAMILIARITY AND FRAMING OF RATE FENCES Familiar Rate Fence (Lunch/Dinner Pricing) With Price Difference Framed as Discount (Surcharge):}

Imagine that on your last visit to a restaurant in a 5-star hotel, you were told that the restaurant is adopting a new pricing policy for weekend buffets. The price for a weekend dinner (lunch) buffet is $\$ 404-++(\$ 30+++)$ and a discount of $\$ 10$ is given for a weekend lunch buffet (an additional $\$ 10$ is charged for a weekend dinner buffet).

\section{Unfamiliar Rate Fence (Duration Control Pricing) With Price Difference Framed as Discount (Surcharge):}

Imagine that on your last visit to a restaurant in a 5-star hotel, you were told that the restaurant is adopting a new pricing policy for weekend buffets. If the time taken for a meal (check opening to check closing) exceeds (is within) 60 minutes, the price of the weekend dinner buffet is $\$ 40+++(\$ 30+++)$. If it is within 60 minutes, a discount of $\$ 10$ is given. (If it exceeds 60 minutes, an additional $\$ 10$ is charged).

Note: +++ stands for net price, plus $10 \%$ service charge and $6 \%$ taxes. This is the standard way in Singapore to post restaurant prices. 


\section{STUDY 2: MANIPULATIONS OF FRAMING AND FENCING CONDITION}

\section{Price Difference Framed as Discount in Fence Advantaged (Disadvantaged) Condition:}

The room reservation rates for a night at an international hotel are as follows:

- If the reservation is made through the hotel Web site, the price is US\$105.

- If the reservation is made through a third-party Web site (e.g., Expedia, Travelocity, Priceline.com), the above price is discounted by US\$25.

Now, imagine you have just reserved a room through a third-party Web site (the hotel Web site) for a short trip. There are no differences in the quality/service standards between the rooms reserved through either means.

\section{Price Difference Framed as Surcharge in Fence Advantaged (Disadvantaged) Condition:}

The room reservation rates for a night at an international hotel are as follows:

- If the reservation is made through a third-party Web site (e.g., Expedia, Travelocity, Priceline.com), the price is US\$80.

- If the reservation is made through the hotel Web site, an additional US\$25 is charged.

Now, image you have just reserved a room through a third-party Web site (the hotel Web site) for a short trip. There are no differences in the quality/service standards between the rooms reserved through either means. 
Table 1. Main types of rate fences

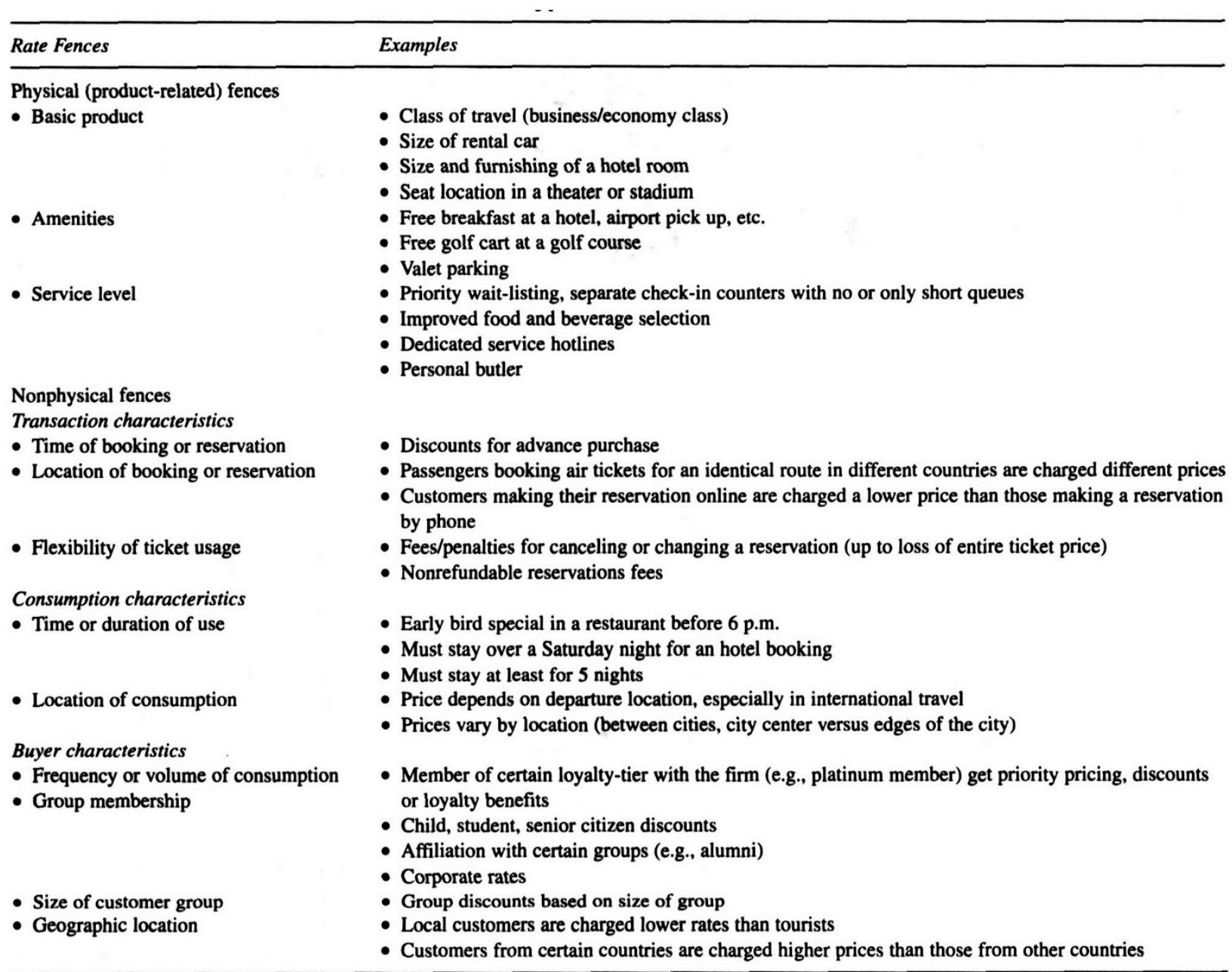

NOTE: A range of fences (often physical and nonphysical) are typically combined in service pricing schedules. This table was adapted from Lovelock and Wirtz (2007, p. 140). 
Table 2. Perceived fairness mean scores by experimental condition.

\begin{tabular}{lll}
\hline & \multicolumn{2}{c}{ Perceived Fairness } \\
\cline { 2 - 3 } & Low Familiarity & High Familiarity \\
\hline Study 1 (Restaurant) & & \\
Framing & & \\
- Discount & $4.18(1.62)$ & $4.40(1.27)$ \\
- Surcharge & $3.08(1.50)$ & $4.34(1.36)$ \\
Study 2 (Hotel) & & \\
Fence advantaged & & \\
- Discount & & \\
- Surcharge & $4.54(1.33)$ & $4.27(1.20)$ \\
Fence disadvantaged & $3.20(1.17)$ & $4.40(1.31)$ \\
- Discount & & \\
- Surcharge & $3.28(1.23)$ & $4.48(1.63)$ \\
\hline
\end{tabular}

NOTE: Standard deviations are provided in parentheses. 
Table 3. Studies 1 and 2 ANOVA results on perceived fairness.

\begin{tabular}{|c|c|c|c|c|c|c|}
\hline Source of Variation & df & Sum of Squares & Mean Square & $\mathbf{F}$ & $\mathrm{p}$ & Eta Square \\
\hline \multicolumn{7}{|l|}{ Study 1 (Restaurant) } \\
\hline Familiarity & 1 & 37.1 & 37.1 & 17.8 & $<.001$ & .06 \\
\hline Framing & 1 & 22.3 & 22.6 & 10.9 & $<.01$ & .04 \\
\hline Familiarity $\times$ Framing & 1 & 18.0 & 18.0 & 8.6 & $<.01$ & .03 \\
\hline Error & 266 & 554.0 & 2.1 & & & \\
\hline Total & 269 & 628.4 & & & & \\
\hline \multicolumn{7}{|l|}{ Study 2 (Hotel) } \\
\hline Familiarity & 1 & 33.5 & 33.5 & 21.5 & $<.001$ & .10 \\
\hline Framing & 1 & 10.3 & 10.3 & 6.6 & $<.05$ & .03 \\
\hline Fencing condition (FC) & 1 & 7.2 & 7.2 & 4.6 & $<.05$ & .02 \\
\hline Familiarity $\times$ Framing & 1 & 7.7 & 7.7 & 4.9 & $<.05$ & .03 \\
\hline Familiarity $\times$ FC & 1 & 7.7 & 7.7 & 5.0 & $<.05$ & .03 \\
\hline Framing $\times$ FC & 1 & 0.5 & 0.5 & 0.3 & $>.10$ & $n s$ \\
\hline Three-way interaction & 1 & 3.8 & 3.8 & 2.4 & $>.10$ & $n s$ \\
\hline Error & 162 & 252.7 & 1.6 & & & \\
\hline Total & 169 & 321.7 & & & & \\
\hline
\end{tabular}




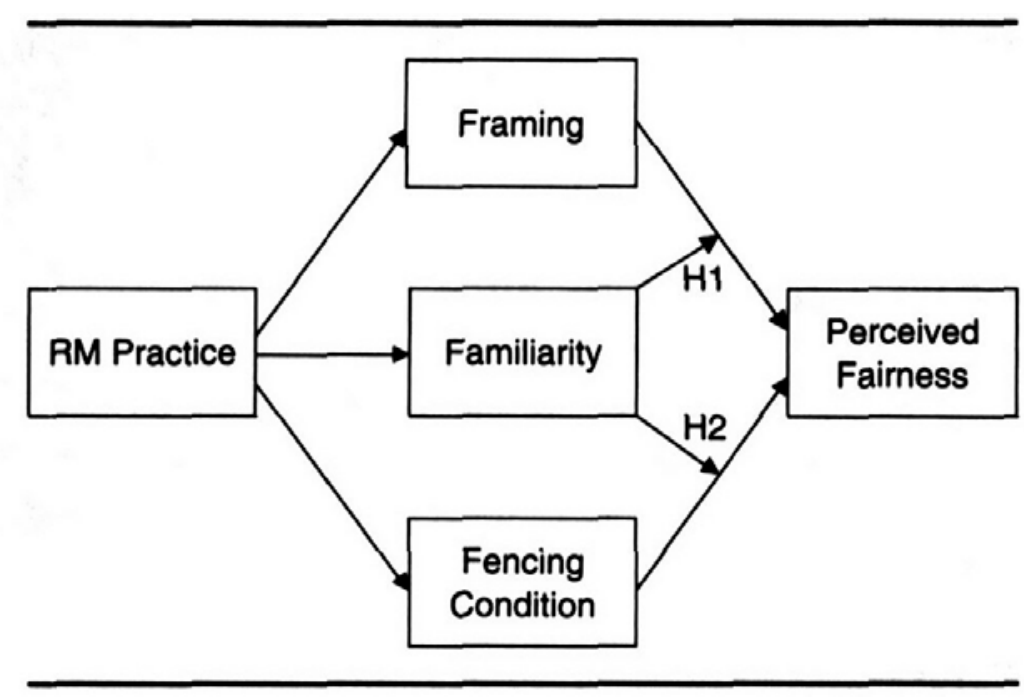

Figure 1. Perceived fairness of Revenue Management (RM) practices as a function of familiarity, framing, and fencing condition. 


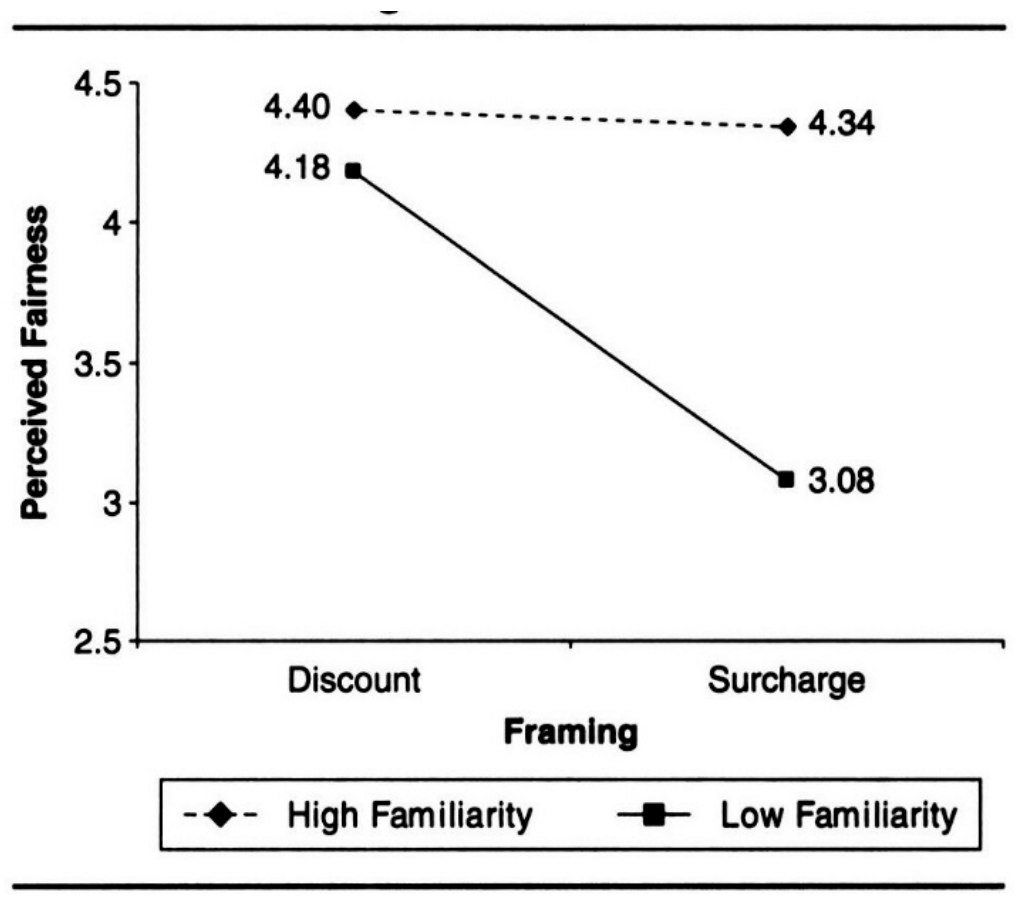

Figure 2. Study 1: Interaction effect of familiarity and framing on perceived fairness. 


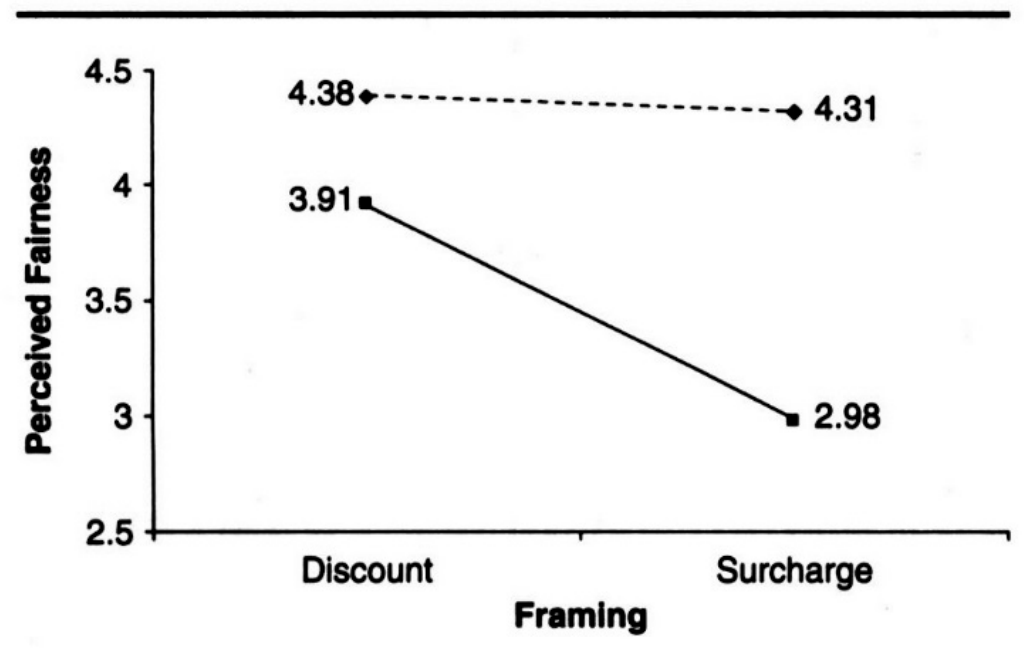

$-\diamond-$ High Familiarity $\rightarrow-$ Low Familiarity

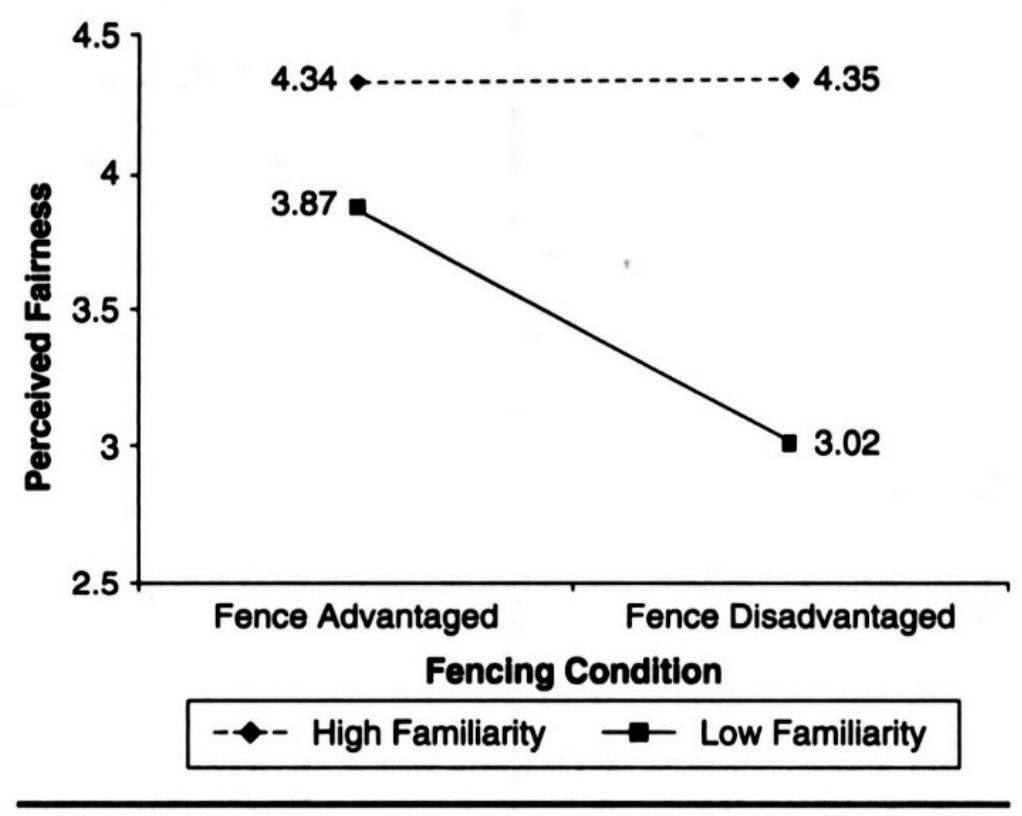

Figure 3. Study 2: Interaction effects on perceived fairness. 


\section{REFERENCES}

Austin, W., N. C. McGinn, and C. Susmilch (1980), "International Standards Revisited: Effects of Social Comparisons and Expectancies on Judgment of Fairness and Satisfaction," Journal of Experimental Social Psychology, 16 (5), 426-41.

Bateson, John E. G. and Michael Hui (1992), "The Ecological Validity of Photographic Slides and Videotapes in Simulating the Service Setting," Journal of Consumer Research, 19 (September), 271-81.

Bies Robert J. and Debra L. Shapiro (1987), "International Fairness Judgments: The Influence of Causal Accounts," Social Justice Research, 1, 199-218.

Bolton, Lisa E., Luk Warlop, and Joseph W. Alba (2003), "Consumer Perceptions of Price (Un)Fairness," Journal of Consumer Research, 29 (4), 474-92.

Born, Chris, Monica Carbajal, Pat Smith, Mark Wallace, Kirk Abbott, Surain Adyanthaya, E. Andrew Boyd, Curds Keller, Jin Liu, Wayne New, Tom Rieger, Bert Winemiller, and Ron Woestemeyer (2004), "Contract Optimization at Texas Children's Hospital," Interfaces, 34(1), 51-8.

Campbell, Margaret C. (1999), "Perceptions of Price Unfairness: Antecedents and Consequences," Journal of Marketing Research, 36(2), 187-99.

Carroll, William J. and Richard C. Grimes (1995), "Evolutionary Change in Product Management: Experiences in the Car Rental Industry," Interfaces, 25 (5), 84-104.

Chen, Shih-Fen S., Kent B. Monroe, and Yung-Chien Lou (1998), "The Effects of Framing Price Promotion Messages on Consumers' Perceptions and Purchase Intentions," Journal of Retailing, 74 (3), 353-72. 
Cook, Thomas C. and Donald T. Campbell (1979), QuasiExperimentation: Design and Analysis Issues for Field Settings. Chicago: Rand McNally.

Dabholkar, Pratibha A. (1996), "Consumer Evaluation of New Technology-Based Self-Service Options: An Investigation of Alternative Models of Service Quality," International Journal of Research in Marketing, 13, 234-46.

Geraghty, M. Karen and Ernest Johnson (1997), "Revenue Management Saves National Car Rental," Interfaces, 27 (1), 107-27.

Greenburg, Jerald (1988), "Using Social Accounts to Manage Impressions of Performance Appraisal Fairness," In Communicating Fairness in Organizations, Co-chairs. J. Greenburg and R. J. Bies, Symposium presented at the Academy of Management, Anaheim, CA.

Hanks, Richard B., R. Paul Noland, and Robert G. Cross (1992), "Discounting in the hotel Industry, a New Approach," Cornell Hotel and Restaurant Administration Quarterly, 33 (3), 40-5.

Havlena, William J. and Morris B. Holbrook (1986), "The Varieties of Consumption Experience: Comparing Two Typologies of Emotion in Consumer Behavior," Journal of Consumer Research, 13, 394-404.

Huppoertz, John W., Sidney J. Arenson, and Richard H. Evans (1978), "An Application of Equity Theory to Buyer-Seller Exchange Situations," Journal of Marketing Research, 15 (May), 250-60.

Kahneman, Daniel and Amos Tversky (1979), "Prospect Theory: An Analysis of Decision Under Risk," Econometrica, 47 (2), 263-91. 
, Jack L. Knetsch. and Richard H. Thaler (1986a), "Fairness as a Constraint on Profit seeking: Entitlements in the Market," American Economic Review, 76, 728-41. , and ___ (1986b), "Fairness and the Assumptions of Economics, " Journal of Business, 59 (4), 285-300.

Kimes, Sheryl E. (1994), "Perceived Fairness of Yield Management," Cornell Hotel and Restaurant Administration Quarterly, 29 (1), 22-29. and Richard B. Chase (1998), "The Strategic Levers of Yield Management," Journal of Service Research, 1 (2), 156-66. and Breffni M. Noone (2002), "Perceived Fairness of Yield Management: An Update," Cornell Hotel and Restaurant Administration Quarterly, 43 (1), 28-9. and Jochen Wirtz (2003a), "Has Revenue Management Become Acceptable? Findings from an International Study on the Perceived Fairness of Rate Fences," Journal of Service Research, 6(2), 125-35. and ___ (2003b), "Perceived Fairness of Revenue Management in the US Golf Industry," Journal of Revenue and Pricing Management, 1 (4), 322-44.

Lovelock Christopher and Jochen Wirtz (2007), Services Marketing: People, Technology, Strategy, 6th ed. Upper Saddle River, New Jersey: Prentice Hall.

Major, Brenda (1994), "From Social Inequality to Personal Entitlement: The Role of Social Comparisons, Legitimacy, Appraisals, and Group Membership," in Advances in Experimental Social Psychology, Vol. 26, Mark P. Zanna, ed. New York: Academic Press. 293-355. 
Martins, Marielza (1995), "An Experimental Investigation of the Effects of Perceived Price Fairness on Perceptions of Sacrifice and Value." Doctoral dissertation, Department of Business Administration, University of Illinois at Urbana-Champaign.

Ng, Irene C. L., Jochen Wirtz, and Khai Sheang Lee (1999), "The Strategic Role of Unused Service Capacity," International Journal of Service Industry Management, 10 (2), 21138.

Oliver, Richard L. and William O. Bearden (1985), "Crossover Effects in the Theory of Reasoned Action: A Moderating Influence Attempt," Journal of Consumer Research, 12 (December), 324-40. and John E. Swan (1989a), "Consumer Perceptions of Interpersonal Equity and Satisfaction in Transactions: A Field Survey Approach," Journal of Marketing, 53 (April), 21-35. and (1989b), "Equity and Disconfirmation Perceptions as Influences on Merchant and Product Satisfaction," Journal of Consumer Research, 16 (December), 372-83.

Ordóñez, Lisa D., Terry Connolly, and Richard Coughlan (2000), "Multiple Reference Points in Satisfaction and Fairness Assessment," Journal of Behavioral Decision Making, 13 (3), 329-44.

Smith, Barry C., John F. Leimkuhler, and Ross M. Darrow (1992), "Yield Management at American Airlines," Interfaces, 22 (1), 8-31.

Thaler, Richard F. (1985), "Mental Accounting and Consumer Choice," Marketing Science, 4 (3), 199-214.

Weiner, Bernard (1985), "An Attributional Theory of Achievement Motivation and Emotion," Psychological Review, 92 (4), 548-73. 
Winer, Russell S. (1986), "A Reference Price Model of Brand Choice for Frequently Purchased Products," Journal of Consumer Research, 13 (September), 250-56.

Wirtz, Jochen and John E.G. Bateson (1999), "Consumer Satisfaction with Services: Integrating the Environmental Perspective in Services Marketing into the Traditional Disconfirmation Paradigm," Journal of Business Research, 44 (1), 55-66. , Sheryl E. Kimes, Jeannette P. T. Ho, and Paul Patterson (2003), "Revenue Management: Resolving Potential Customer Conflicts," Journal of Revenue and Pricing Management, 2 (3), 216-28.

Xia, Lan, Kent B. Monroe, and Jennifer L. Cox (2004), "The Price Is Unfair! A Conceptual Framework of Price Fairness Perceptions," Journal of Marketing, 68 (October), 1-15. 